Research Paper

\title{
Efficacy and Safety of 1\% Atropine on Retardation of Moderate Myopia Progression in Chinese School Children
}

\author{
Qin Zhu ${ }^{1 *}$, Yang Tang ${ }^{*}$, Liyun Guo ${ }^{1 *}$, Sean Tighe ${ }^{2}$, Yuan Zhou1, Xiaofan Zhang ${ }^{1}$, Jieying Zhang1, Yingting \\ $\mathrm{Zhu}^{2}$ and Min $\mathrm{Hu}^{1}{ }^{\circledR}$ \\ 1. Department of Ophthalmology, The Second People's Hospital of Yunnan Province (Fourth Affiliated Hospital of Kunming Medical University); Yunnan Eye \\ Institute; Key Laboratory of Yunnan Province for the Prevention and Treatment of ophthalmology (2017DG008); Provincial Innovation Team for Cataract \\ and Ocular Fundus Disease (2017HC010); Expert Workstation of Yao Ke (2017IC064), Kunming 650021, China \\ 2. Tissue Tech, Inc., Ocular Surface Center, and Ocular Surface Research \& Education Foundation, Miami, FL, 33126 USA \\ * The first three authors contribute equally to this work.
}

$\triangle$ Corresponding authors: Min Hu, M.D., Ph.D. Department of Ophthalmology, Fourth Affiliated Hospital of Kunming Medical University, Second People's Hospital of Yunnan Province, Kunming 650021, China; Telephone: 0118615087162600; Fax: 011860871-65156650; E-mail: fudanhumin@sina.com or Yingting Zhu, D.V.M., Ph.D. TissueTech, Inc., 7300 Corporate Center Drive, Suite B, Miami, FL 33126. Telephone: (786) 456-7632; Fax: (305) 274-1297; E-mail: yzhu@tissuetechinc.com

(C) The author(s). This is an open access article distributed under the terms of the Creative Commons Attribution License (https://creativecommons.org/licenses/by/4.0/). See http://ivyspring.com/terms for full terms and conditions.

Received: 2019.08.15; Accepted: 2019.11.18; Published: 2020.01.01

\begin{abstract}
Background: To evaluate the long-term efficacy and safety of topical $1 \%$ atropine for retarding moderate myopia.

Methods: A randomized, controlled study evaluating atropine and placebo in 660 Chinese children. Patients received drops q lmonth for 24 months, then q2month for 12 months, followed by no drops for 12 months. Spherical equivalent, axial length, intraocular pressure and atropine-related side effects were examined at $6,12,24,36$ and 48 months for all children.

Results: Spherical equivalent, myopic progression, axial length augmentation, and progression rate were significantly reduced in the atropine group than those in the placebo group (all $\mathrm{P}<0.05$ ), indicating that $1 \%$ atropine effectively retarded myopia. Moreover, myopic rebound and adverse effects of $1 \%$ atropine were eliminated by gradual withdrawal and elimination of $1 \%$ atropine. Furthermore, pupil size, near visual acuity, and amplitude of accommodation returned to pretreatment levels after withdrawal of atropine.

Conclusion: Topical 1\% atropine periodically and alternatively in phase I with gradual reduction in phase II and final withdrawal in phase III may effectively improve atropine efficacy, retard moderate myopia, reduce atropine side effects, minimize myopic rebound, and increase compliance of children simultaneously.
\end{abstract}

Key words: atropine, myopia, therapeutic effect, Chinese children

\section{Introduction}

Myopia is a major public health concern that has become increasingly common [1]. The overall prevalence of myopia has increased from $79.5 \%$ to $87.7 \%$, with a significant increase of moderate myopia (38.8\% to $45.7 \%)$, severe myopia $(7.9 \%$ to $16.6 \%)$, and terminal myopia $(0.08 \%$ to $0.92 \%)$ [2]. In China, the prevalence of myopia is $27 \%$ in primary school students and as high as $81 \%$ in high-school students
$[3,4]$. Unfortunately, severe myopia has become one of the main causes of untreatable vision loss throughout the world, often due to its irreversible complications, such as retinal detachment, retinal break, macular degeneration, choroidal neovascularization and glaucoma [5-8]. The risk of these complications increases with the severity of myopia and the early onset of myopia in childhood is associated with the 
severity of myopia in the adult life [9-12].

The most common form of myopia worldwide is secondary to elongation of the axial length of the eye, termed axial myopia. Axial lengthening begins in childhood and progresses remarkably during the adolescent growth period. In this period, the risk of myopia-related complications increases proportionately with axial length. Therefore, the most effective strategy to reduce myopia-related complications is to delay myopia progression during childhood $[13,14]$.

At present, options for retarding myopia progression include progressive addition of executive bifocal spectacle lenses [15-17], peripheral defocusing lenses [18], contact lenses [19], overnight orthokeratology [20-22], multifocal soft contact lenses [23], outdoor activities [24], and pharmacological agents [25]. Unfortunately, long-term outcomes using bifocals, progressive addition lenses, and contact lenses have been unsatisfactory in myopia control (reviewed in [18]). Alternatively, pharmacological intervention using atropine has gained recent interest based on results from the Atropine for the treatment of childhood myopia (ATOM) study. [26-31] This doubleblinded study showed topical atropine was well tolerated and effective in slowing the progression of low and moderate myopia and ocular axial elongation in Asian children. Despite these satisfactory results, a proper treatment regimen for effective treatment of myopia by atropine has not been established. In addition, there is concern of possible long-term side effects of $1 \%$ atropine eye drops, including phototoxic effects on the retina and lens [32], near vision blurring, photophobia, allergic reaction, and myopic rebound after the treatment is discontinued [33].

Previously we evaluated if lowering the concentration of atropine from $1 \%$ to $0.01 \%$ would result in safer outcomes. [34] Unfortunately, the lower concentration was not effective in preventing myopia progression. Therefore, the present study was designed to evaluate a modified dosing regimen of $1 \%$ atropine in decreasing side effects and retarding myopia progression. Our results suggest that this issue can be satisfactorily resolved by using $1 \%$ atropine periodically and alternatively in phase I, with gradual reduction in phase II and elimination in phase III. Such a treatment may not only significantly and effectively slowdown the progression of myopia, but also profoundly reduce the side effects of atropine and minimize myopic rebound.

\section{Materials and Methods}

\section{Design}

The design was an effectiveness study, prospective and clinic-based. This study followed the tenets of the Helsinki Declaration on ethical principles for medical research involving human subjects and was approved by the Committee for Protection of Human Subjects (CPHS) of Yunnan Eye Research Institute Review Board, the Second People's Hospital of Yunnan Province, China. Children were recruited in the hospital from December 2014 to December 2018. The informed written consent was obtained from all subjects prior to participation in the study after the nature of the study and the possible outcomes were disclosed.

Assignments to the control (placebo) and the experimental ( $1 \%$ atropine) groups were allocated with concealment according to a computer-generated randomization list after eligibility criteria were verified. The children had, therefore, an equal probability of assignment to either the experimental group or the control group. As a result, 330 children from the experimental group and 330 children from the control group were enrolled in this investigation. A study number was issued to each child. The plan was adhered strictly to the experimental design specified below in the entire trial.

\section{Criteria}

In the meta-analysis, the subjects met the following criteria: (1) Initial myopic spherical equivalent ranged of $-2.0 \mathrm{D}$ to $-8.00 \mathrm{D}$, and astigmatism $\leq 1.0 \mathrm{D}$. (2) Recruited children age was between 6 to 12 years, willing to participate in the entire 4-year trial. (3) SE progression rate was $\geq 1 \mathrm{D} /$ Year in the last year. (4) Binocular function and stereopsis were normal. (5) Intraocular pressure was normal (IOP $<21 \mathrm{mmHg}$ ). (6) Ability against cycloplegia and mydriasis was a must.

The exclusion criteria were as follows: (1) Children with ocular diseases, such as amblyopia, strabismus, congenital cataract, glaucoma, corneal scar, optic neuropathy, traumatic ocular injury, uveitis, or ocular tumor were excluded. (2) Children with history of any ocular surgeries were excluded. (3) Any systemic diseases or conditions that could affect visual function and development, including diabetes mellitus and/or chromosome anomaly, were excluded. (4) Previous or current use of contact lenses, bifocals, progressive addition lenses, or other forms of treatment, including atropine, for the control of myopia were excluded.

Only those patients whose families formally confirmed $100 \%$ compliance to the treatment and who had more than 1 year follow up (during this year's follow-up, myopia progression $>1 \mathrm{D} /$ year) were included in the study. Both parents and children are required to fill in questionnaire surveys, including the time and the quantity of eye drops received, the adverse events and the duration. 


\section{Subjects and Experiments}

Six hundred and sixty myopic school children met the above criteria were included in the study. The experimental group, including 330 myopic children in phase I, according to their chart records, received topical 1\% atropine eye drops (Xingqi Pharmaceutical Co., Ltd. China) at bedtime once a month (one eye received treatment at day 1 , the other eye received treatment at day 16) for 24 months. Spherical equivalent (SE) and axial length (AL) were determined for the children at 6-month interval. Intraocular pressure (IOP) and potential atropine-related side effects were evaluated at 6-month interval. In phase II, the frequency of the medication was reduced to once two-months, for 12 months. The examinations specified above were also at 6-month interval. In phase III, no atropine was applied to the children for 12 months (withdrawal of atropine). During the three stages, 330 children received the corresponding treatment of saline (placebo) and frame glasses as the controls. All children in the control group were examined similarly as those in the experimental group.

During this study, photo chromatic progressive addition lenses with ultraviolet protection were used to minimize the photophobia, glare, and potential toxicity to the retina and lens due to long-term dilation and exposure to ultraviolet light.

Cycloplegic autorefraction was obtained 45 minutes after administration of $1 \%$ cyclopentolate eye drops, performed by investigators who were trained in the study protocols by Topcon auto refractor KR8 900 (Topcon, Tokyo, Japan). Uncooperative children refractive error was determined by the experienced orthoptist (JRP) performing retinoscopy with a Heine beta 200 retinoscope (Heine Optotechnik, Herrsching, Germany) and the lenses according to the standard protocols. Spherical equivalent was calculated using the standard formula: ( $\mathrm{SE}=$ sphere $+1 / 2$ cylinder). After cycloplegic refraction, axial length was measured by IOL Master 500 (Carl Zeiss MEDITEC IOL-master, Jena, Germany). IOPs were obtained via noncontact tonometry (Nidek Co. Ltd, Tokyo, Japan). Initial ocular investigations at our hospital included slit lamp biomicroscopic examination for anterior segment, direct or indirect ophthalmoscopic examination for vitreous, retina and optic disc evaluation. All control cases were matched with the experimental cases in terms of age, sex, and initial SER $( \pm 0.50 \mathrm{D})$, to avoid potential bias. The control cases received the same ophthalmic examinations as the experimental subjects. At each follow-up visit, all children were required to change their glasses if the $S E$ progression rate $\geq 0.5 \mathrm{D}$.

During each visit, children and parents were given an open-ended opportunity to report any medical illness or side effects, including any symptoms related to allergy, blurred near vision, glare, or visual loss. The details of such reports were documented.

\section{Statistical Analysis}

All statistical analyses were based on the intention-to-treatment principle and performed using SAS software version 9.13 (Cary, NC). For continuous variables such as age, the duration of follow-up, and spherical equivalent refraction, analysis of variance and the Student's t-test was used to determine the statistical significance between the groups. For continuous variables, such as unaided visual acuity, spherical equivalent refraction and axial length, analysis of variance of repeated measure data was used to determine the statistical significance between the groups. The $x^{2}$ test was used to compare the categorical variables. Throughout the study, $\mathrm{P}<0.05$ was considered as statistically significant.

\section{Results}

Between December 2014 and December 2018, 660 children were randomly enrolled in the study, of which 330 from the experimental group and 330 from the control group. At the initial pretreatment visit, there was no significant statistical difference between the two groups in mean sex, age, spherical equivalent, axial length, biometric characteristics and parental myopia (all $\mathrm{P}>0.05$, Table 1-3).

Table 1. Baseline Demographic Characteristics

\begin{tabular}{llll}
\hline Characteristics & $\begin{array}{l}\text { Experimental Group } \\
\text { (n=262) }\end{array}$ & $\begin{array}{l}\text { Control Group } \\
\text { (n=308) }\end{array}$ & P Value \\
\hline Male/Female & $130 / 132$ & $156 / 152$ & 0.22 \\
Age & $9.11 \pm 0.09$ & $9.19 \pm 0.14$ & 0.10 \\
Initial SER, D & $-3.82 \pm 0.44$ & $-3.74 \pm 0.51$ & 0.29 \\
Axial Length & $24.93 \pm 0.21$ & $24.91 \pm 0.18$ & 0.28 \\
\hline
\end{tabular}

Table 2. Parental Myopia and Age

\begin{tabular}{llll}
\hline & Experimental Group & Control Group & P Value \\
\hline SE of Mother & $3.26 \pm 3.17$ & $3.29 \pm 3.23$ & 0.16 \\
SE of Father & $4.01 \pm 3.83$ & $4.12 \pm 3.91$ & 0.28 \\
Age of Mother & $27.91 \pm 5.68$ & $28.12 \pm 5.09$ & 0.10 \\
Age of Father & $28.71 \pm 6.87$ & $28.81 \pm 6.47$ & 0.43 \\
\hline
\end{tabular}

A total of $570(86.4 \%)$ subjects completed the 4 -year study. Of 90 cases who did not, 22 were from the control group and 68 were from the experimental group. The most frequent reasons for discontinuation in the experimental group were photophobia and reading problems within the first month. As the children continued to take the medication of $1 \%$ atropine for more than three months, the adverse 
reactions became very mild, according to the questionnaire. In addition, the reading difficulties of most children were significantly reduced after three months of medication and the rate of interruption greatly decreased. Only those patients who did not miss the medication during the trial period were included in the analysis.

Table 3. Spherical Equivalent and Axial Length over Time in Treatment Group and Control Group

\begin{tabular}{|c|c|c|c|}
\hline & $\begin{array}{l}\text { Experimental } \\
\text { Group } \\
(\mathrm{n}=262)\end{array}$ & $\begin{array}{l}\text { Control } \\
\text { Group } \\
(n=308)\end{array}$ & $\begin{array}{l}P \\
\text { Value }\end{array}$ \\
\hline \multicolumn{4}{|l|}{ Spherical Equivalent Refraction (SER) } \\
\hline Before Treatment (D) & $-3.82 \pm 0.44$ & $-3.74 \pm 0.51$ & 0.30 \\
\hline 6 Months after Treatment (D) & $-3.91 \pm 0.35$ & $-4.15 \pm 0.89$ & 0.03 \\
\hline 12 Months after Treatment (D) & $-4.05 \pm 0.97$ & $-4.79 \pm 0.82$ & 0.020 \\
\hline 18 Months after Treatment (D) & $-4.11 \pm 0.80$ & $-5.21 \pm 0.88$ & 0.016 \\
\hline 24 Months after Treatment (D) & $-4.27 \pm 0.21$ & $-5.68 \pm 1.03$ & 0.011 \\
\hline 30 Months after Treatment (D) & $-4.41 \pm 0.93$ & $-6.12 \pm 0.73$ & 0.009 \\
\hline 36 Months after Treatment (D) & $-4.58 \pm 1.32$ & $-6.59 \pm 1.10$ & 0.006 \\
\hline 48 Months after Treatment (D) & $-4.96 \pm 1.22$ & $-7.28 \pm 1.26$ & $<0.001$ \\
\hline \multicolumn{4}{|l|}{ Myopic Progression Rate (PR) } \\
\hline Before Treatment & $-1.28 \pm 0.81$ & $-1.29 \pm 0.13$ & 0.62 \\
\hline 6 Months after Treatment (D/year) & $-0.27 \pm 0.16$ & $-1.01 \pm 0.49$ & $<0.001$ \\
\hline 12 Months after Treatment (D/year) & $-0.24 \pm 0.22$ & $-0.98 \pm 0.90$ & $<0.001$ \\
\hline 18 Months after Treatment (D/year) & $-0.22 \pm 0.14$ & $-0.91 \pm 0.61$ & $<0.001$ \\
\hline 24 Months after Treatment (D/year) & $-0.21 \pm 0.22$ & $-0.89 \pm 0.23$ & $<0.001$ \\
\hline 30 Months after Treatment (D/year) & $-0.29 \pm 0.19$ & $-0.82 \pm 0.14$ & $<0.001$ \\
\hline 36 Months after Treatment (D/year) & $-0.31 \pm 0.29$ & $-0.80 \pm 0.66$ & 0.008 \\
\hline 48 Months after Treatment (D/year) & $-0.41 \pm 0.23$ & $-0.75 \pm 0.64$ & 0.012 \\
\hline \multicolumn{4}{|l|}{ Axial Length (AL) } \\
\hline Before Treatment & $24.93 \pm 0.21$ & $24.91 \pm 0.18$ & 0.30 \\
\hline 6 Months after Treatment (mm) & $25.00 \pm 0.18$ & $25.13 \pm 0.12$ & 0.16 \\
\hline 12 Months after Treatment (mm) & $25.03 \pm 0.11$ & $25.34 \pm 0.08$ & 0.126 \\
\hline 18 Months after Treatment (mm) & $25.10 \pm 0.15$ & $25.57 \pm 0.14$ & 0.018 \\
\hline 24 Months after Treatment (mm) & $25.18 \pm 0.21$ & $25.72 \pm 0.17$ & 0.009 \\
\hline 30 Months after Treatment (mm) & $25.26 \pm 0.18$ & $25.98 \pm 0.13$ & 0.002 \\
\hline 36 Months after Treatment (mm) & $25.31 \pm 0.14$ & $26.18 \pm 0.14$ & 0.001 \\
\hline 48 Months after Treatment (mm) & $25.48 \pm 0.29$ & $26.59 \pm 0.20$ & $<0.001$ \\
\hline \multicolumn{4}{|l|}{ AL Progression Rate (PR) } \\
\hline Before Treatment & $0.41 \pm 0.27$ & $0.42 \pm 0.26$ & 0.9 \\
\hline 6 Months after Treatment (mm/year) & $0.11 \pm 0.13$ & $0.41 \pm 0.19$ & $<0.001$ \\
\hline 12 Months after Treatment (mm/year) & $0.12 \pm 0.10$ & $0.40 \pm 0.06$ & $<0.001$ \\
\hline 18 Months after Treatment (mm/year) & $0.12 \pm 0.16$ & $0.40 \pm 0.11$ & $<0.001$ \\
\hline 24 Months after Treatment (mm/year) & $0.12 \pm 0.10$ & $0.39 \pm 0.19$ & $<0.001$ \\
\hline 30 Months after Treatment (mm/year) & $0.13 \pm 0.06$ & $0.39 \pm 0.04$ & $<0.001$ \\
\hline 36 Months after Treatment (mm/year) & $0.14 \pm 0.09$ & $0.39 \pm 0.14$ & $<0.001$ \\
\hline 48 Months after Treatment (mm/year) & $0.19 \pm 0.13$ & $0.40 \pm 0.16$ & $<0.001$ \\
\hline
\end{tabular}

At the end of phase I (i.e. 24 months), the mean progression of myopia in $1 \%$ atropine group was significantly reduced when compare to that in the control group $[(-0.27 \pm 0.81 \mathrm{D}) /$ Year vs $(-1.29 \pm 0.13$ D)/Year, $\mathrm{P}<0.05$, Table 3]. In addition, axial length increase in the experimental group was also significantly decreased when compared to that in the control group $[(0.11 \pm 0.13 \mathrm{~mm}) /$ Year vs $(0.41 \pm 0.19$ $\mathrm{mm}) /$ Year, $\mathrm{P}<0.05$, Table 3]. At the end of the second phase (25-36 months), the mean progression of myopia in the $1 \%$ atropine group was significantly diminished when compared to that in the control group $[(-0.31 \pm 0.29 \mathrm{D}) /$ Year, vs $(-0.80 \pm 0.66 \mathrm{D})$ /Year $\mathrm{P}<0.01$, Table 3]. The mean increase in axial length in the atropine group was profoundly reduced when compared to that in the control group $[(0.14 \pm 0.09$ $\mathrm{mm}) /$ Year vs $(0.39 \pm 0.14 \mathrm{~mm}) /$ Year, $\mathrm{P}<0.001$, Table 3]. Furthermore, at the end of phase III (36-48 months), myopia progression in $1 \%$ atropine group was significantly decreased when compared to that in the control group $[(-0.41 \pm 0.23$ D)/Year vs $(-0.75 \pm 0.64$ D)/Year, $P<0.05$, Table 3]. The mean increase in axial length in the experimental group was also significantly diminished when compared to that in the control group $[(0.19 \pm 0.13 \mathrm{~mm}) /$ Year vs $(0.40 \pm 0.16$ $\mathrm{mm}) /$ Year, $\mathrm{P}<0.001$, Table 3].

Interestingly, at the end of the 4-year study, the final SER in 1\% atropine group was significantly reduced when compared to that in the control group [(-4.96 $\pm 1.22 \mathrm{D})$ vs $(-7.28 \pm 1.26 \mathrm{D}), \mathrm{P}<0.001$, Table 3]. In addition, the final AL in the experimental group was significantly reduced when compared to that in the control group [(25.48 $\pm 0.29 \mathrm{~mm})$ vs $(26.59 \pm 0.20 \mathrm{~mm})$, $\mathrm{P}<0.01$, Table 3]. Furthermore, the final mean myopia progression per year (mean myopia progression rate) in the experimental group was significantly decreased when compared to that in the control group [(-0.29 \pm $0.17 \mathrm{D})$ vs $(-0.89 \pm 0.44 \mathrm{D}), \mathrm{P}<0.05$, Table 3]. Finally, all $288(100 \%)$ children in the control group had faster myopia progression, defined as myopia progression greater than $-0.5 \mathrm{D}$ per year, in contrast to $46(16.3 \%$, out of 282) children in the experimental group.

Meanwhile, at the end of follow-up, pupil size and near visual acuity returned to pre-atropine levels in both groups. In addition, the amplitude of accommodation and near visual acuity also returned to the pretreatment levels. Furthermore, throughout the follow-up period, no serious adverse events related to atropine were noted. Adverse events in children who maintained and ceased therapy in treatment group were: photophobia 205/330 (62.12\%), blurred near vision $65 / 330(19.70 \%)$, allergic reaction $3 / 330(0.9 \%)$ eye irritation 61/330 (18.5\%), and infections (conjunctivitis, blepharitis) 18/330 (5.451\%) (Table 4).

Table 4. Adverse Events in Children Who Maintained and Ceased Therapy in the Experimental Group

\begin{tabular}{llll}
\hline & $\begin{array}{l}\text { Maintained Therapy } \\
(\mathbf{n = 2 6 2})\end{array}$ & $\begin{array}{l}\text { Ceased Therapy } \\
\text { (n=68) }\end{array}$ & $\begin{array}{l}\text { Total } \\
\text { (n=330) }\end{array}$ \\
\hline Photophobia & $154 / 262(58.78 \%)$ & $51 / 68(75.0 \%)$ & $205(62.12 \%)$ \\
Blurred Near Vision & $56 / 262(21.37 \%)$ & $9 / 68(13.24 \%)$ & $65(19.70 \%)$ \\
Headache & $36 / 262(12.8 \%)$ & $3 / 68(4.41 \%)$ & $39(11.82 \%)$ \\
Allergic Reaction & $3 / 262(1.1 \%)$ & $0 / 68(0 \%)$ & $3(0.9 \%)$ \\
$\begin{array}{l}\text { Eye Irritation } \\
\begin{array}{l}\text { Infections (Conjuncti- } \\
\text { vitis, Blepharitis) }\end{array}\end{array}$ & $59 / 262(22.52 \%)$ & $2 / 68(2.94 \%)$ & $61(18.5 \%)$ \\
\end{tabular}


The reasons for the withdrawal from the trial were: forget $(12.0 \%)$, photophobia $(10.0 \%)$, eye irritation $(8.2 \%)$. No patients complained distention of eyes, ocular redness, or foreign body sensation, and so forth. No changes were observed in IOPs, crystalline lenses, optics disk, or macula following atropine administration.

According to the records from the parents, the blurred near vision disappeared 4.6 days in average after atropine applications. Because atropine was used in one eye every month instead of both eyes, mild photophobia and blurred near vision did not affect children's daily study and life. Atropine subjects had no-significantly myopic rebound during recovery phase III.

\section{Discussion}

Atropine, an alkaloid derived from Atropa belladonna, acts as an antagonist against the nonselective competitive muscarinic acetylcholine receptors. Topical atropine has previously been shown to delay myopic progression and axial elongation [26] in a dose-dependent manner [28, 34]. The $1 \%$ atropine group has been demonstrated to be the most effective $(78 \%)$ followed by $0.5 \%$ group (75\%), $0.1 \%$ group $(70 \%)$, and $0.01 \%$ group $(50 \%)$ [ 28 , 34]. Unfortunately, long-term side effects have been attributed to $1 \%$ atropine eye drops [33]. Therefore, we carefully designed this clinical study to evaluate $1 \%$ atropine drops only once a month, eye to eye alternatively in the first two years as a treatment period, every 2 months, eye to eye alternatively in the third year as a transition period, and withdrawal of atropine eyedrops in the fourth year in Chinese children to determine if this decreased side effects but maintained effectiveness in retarding myopia progression.

At 2 years, our results showed the mean myopia progression in the atropine group was significantly reduced, when compared with that in the control group $\left[\begin{array}{llllll}-0.45 & \mathrm{D} & (-0.225 \mathrm{D} / \text { Year }) & \text { vs } & -1.94 & \mathrm{D}\end{array}\right.$ $(-0.97 \mathrm{D} /$ Year $)]$. Axial length increase in the experimental group was also significantly decreased, when compared to that from the control group $[(0.25 \pm 0.31 \mathrm{~mm})$ vs $(0.81 \pm 0.39 \mathrm{~mm})]$. These results indicate that myopia progression and axial length increase were reduced by $76.8 \%$ and $69.1 \%$ respectively, similar to the reports that daily use of $1 \%$ atropine slowed down myopia progression and axial elongation by approximately $78 \%$ and $70 \%$ in previous trials $[28,29,31,34,35]$. Thus, we established that $1 \%$ atropine was equally effective in reducing myopia progression when used daily or monthly.

Although 1\% atropine was effective in slowing myopic progression as previously shown in other studies as well (Tran HDM et al, 2018), a significant rebound phenomenon of myopia has been noted.[36] To minimize such a rebound, we reduced the frequency of $1 \%$ atropine from once a month to once every two months from years 2 to 3 , aiming to prevent myopia rebound caused by the withdrawal of atropine abruptly. Interestingly, our results demonstrated that the mean progression of myopia in the atropine group was significantly reduced than that in the control group $[(-0.31 \pm 0.29 \mathrm{D}) /$ Year vs $(-0.80 \pm 0.66 \mathrm{D})$ /Year)], suggesting that reduced frequency of $1 \%$ atropine use is indeed effective to significantly decrease myopia rebound.

Because sudden cessation of atropine drops and high dose (for example, 1\%) has been associated with the rebound in myopia progression $[37,38]$, we chose to add one-year withdrawal period (phase III), aiming at reducing such a rebound. As expected, our results showed that after withdrawal of $1 \%$ atropine for 1 year, the mean progression of myopia in our $1 \%$ atropine group was significantly decreased when compared to those from $1 \%, 0.5 \%, 0.1 \%$ atropine groups in which atropine eyedrops were used daily and withdrew abruptly [(-0.41 $\pm 0.23 \mathrm{D}) /$ Year vs those atropine used daily and withdrew abruptly $1 \%$ group $(-1.14 \pm 0.80 \mathrm{D}), 0.5 \%$ group $(-0.87 \pm 0.52 \mathrm{D}), 0.1 \%$ group $(-0.68 \pm 0.45 \mathrm{D})$ [2]. In addition, myopic rebound in our observation was reduced by two third, when compared to that reported previously [28, 34, 37, 38], suggesting that our method achieved a significant greater reduction in both progression of childhood moderate myopia and myopic rebound by gradually withdrawing the frequency of atropine eye drops in phase III. Our results showed that over the 4-year period, $\sim 68 \%$ reduction in mean progression of myopia and $65 \%$ decrease of axial growth in the experimental eyes were achieved, when compared to those in the control group. Our study also demonstrated that $1 \%$ atropine treatment was well tolerated generally, with no serious adverse effects.

Based on our results, we recommend the following guidelines in controlling myopia: First, identify and discuss the risk factors with the patients and provide lifestyle advice, such as increase of the outdoor time. Second, start intervention with atropine $1 \%$ and photo chromatic glasses in high risky patients. Third, perform regular follow-up examinations including visual acuity, reading acuity, cycloplegic refraction, and axial length. Finally, adjust clinical treatment regimen as we have recommended. When SE and axial length remain stable for a period of 12 months, gradually taper the atropine concentration to naught. 


\section{Conclusion}

In conclusion, our study shows for the first time that our established procedure, treatment of one eye at one time point and the other eye at the other time point with $1 \%$ atropine to achieve frequency of once a month in the first two years and gradually withdrawal of atropine to once two months in the third year with a recovery fourth year can effectively retard the progression of moderate myopia with a significant reduction in myopic rebound in school children. Our method provides a remarkable choice for effectively treatment of myopia in school children, in our daily clinical practice anywhere in the world, thus, preventing mind and moderate myopic children from becoming severe myopia patients later in life.

\section{Acknowledgement s}

This work is supported by the National Natural Science Foundation of China, Grant No. 81560168.

\section{Author Contributions}

Q Zhu, Y Tang and LY Guo have contributed to experimental design, performance of experiments and manuscript writing. $S$ Tighe has contributed to manuscript organizing, writing and English editing. $Y$ Zhou, XF Zhang and JY Zhang have contributed to performance of experiments. $\mathrm{M} \mathrm{Hu}$ and YT Zhu have overseen the experimental design, performance and finalized the manuscripts.

\section{Competing Interests}

The authors have declared that no competing interest exists.

\section{References}

1. Morgan IG, Ohno-Matsui K, Saw SM. Myopia. Lancet. 2012; 379: 1739-48.

2. Chen M, Wu A, Zhang L, Wang W, Chen X, Yu X, et al. The increasing prevalence of myopia and high myopia among high school students in Fenghua city, eastern China: a 15-year population-based survey. BMC Ophthalmol. 2018: 18: 159.

3. Li Y, Liu J, Qi P. The increasing prevalence of myopia in junior high school students in the Haidian District of Beijing, China: a 10-year population-based survey. BMC Ophthalmol. 2017; 17: 88.

4. Xiang F, He M, Zeng Y, Mai J, Rose KA, Morgan IG. Increases in the prevalence of reduced visual acuity and myopia in Chinese children in Guangzhou over the past 20 years. Eye (Lond). 2013; 27: 1353-8.

5. Rada JA, Shelton S, Norton TT. The sclera and myopia. Exp Eye Res. 2006; 82: 185-200

6. Saw SM, Gazzard G, Shih-Yen EC, Chua WH. Myopia and associated pathological complications. Ophthalmic Physiol Opt. 2005; 25: 381-91.

7. Saw SM. How blinding is pathological myopia? Br J Ophthalmol. 2006; 90 : 525-6.

8. Tano Y. Pathologic myopia: where are we now? Am J Ophthalmol. 2002; 134: 645-60.

9. Liang CL, Yen E, Su JY, Liu C, Chang TY, Park N, et al. Impact of family history of high myopia on level and onset of myopia. Invest Ophthalmol Vis Sci. 2004; 45: 3446-52.

10. Thorn F, Gwiazda J, Held R. Myopia progression is specified by a double exponential growth function. Optom Vis Sci. 2005; 82: 286-97.

11. Lam CS, Edwards M, Millodot M, Goh WS. A 2-year longitudinal study of myopia progression and optical component changes among Hong Kong schoolchildren. Optom Vis Sci. 1999; 76: 370-80

12. Chua SY, Ikram MK, Tan CS, Lee YS, Ni Y, Shirong C, et al. Relative Contribution of Risk Factors for Early-Onset Myopia in Young Asian Children. Invest Ophthalmol Vis Sci. 2015; 56: 8101-7.
13. Shih KC, Chan TC, Ng AL, Lai JS, Li WW, Cheng AC, et al. Use of Atropine for Prevention of Childhood Myopia Progression in Clinical Practice. Eye Contact Lens. 2016; 42: 16-23.

14. Tideman JWL, Polling JR, Vingerling JR, Jaddoe VWV, Williams C, Guggenheim JA, et al. Axial length growth and the risk of developing myopia in European children. Acta Ophthalmol. 2018; 96: 301-9.

15. Gwiazda J, Hyman L, Hussein M, Everett D, Norton TT, Kurtz D, et al. A randomized clinical trial of progressive addition lenses versus single vision lenses on the progression of myopia in children. Invest Ophthalmol Vis Sci. 2003; 44: 1492-500.

16. Hasebe S, Ohtsuki H, Nonaka T, Nakatsuka C, Miyata M, Hamasaki I, et al. Effect of progressive addition lenses on myopia progression in Japanese children: a prospective, randomized, double-masked, crossover trial. Invest Ophthalmol Vis Sci. 2008; 49: 2781-9.

17. Berntsen DA, Sinnott LT, Mutti DO, Zadnik K. A randomized trial using progressive addition lenses to evaluate theories of myopia progression in children with a high lag of accommodation. Invest Ophthalmol Vis Sci. 2012; 53: 640-9.

18. Walline JJ, Lindsley K, Vedula SS, Cotter SA, Mutti DO, Twelker JD. Interventions to slow progression of myopia in children. Cochrane Database Syst Rev. 2011; CD004916.

19. Grosvenor T, Perrigin J, Perrigin D, Quintero S. Use of silicone-acrylate contact lenses for the control of myopia: results after two years of lens wear. Optom Vis Sci. 1989; 66: 41-7.

20. Cho P, Cheung SW. Retardation of myopia in Orthokeratology (ROMIO) study: a 2-year randomized clinical trial. Invest Ophthalmol Vis Sci. 2012; 53: 7077-85.

21. Sun $Y, X u$ F, Zhang T, Liu M, Wang D, Chen Y, et al. Orthokeratology to control myopia progression: a meta-analysis. PLoS One. 2015; 10: e0124535.

22. Chan DK, Fung YK, Xing S, Hagger MS. Myopia prevention, near work, and visual acuity of college students: integrating the theory of planned behavior and self-determination theory. J Behav Med. 2014; 37: 369-80.

23. Kang P, McAlinden C, Wildsoet CF. Effects of multifocal soft contact lenses used to slow myopia progression on quality of vision in young adults. Acta Ophthalmol. 2017; 95: e43-e53.

24. Xiong S, Sankaridurg P, Naduvilath T, Zang J, Zou H, Zhu J, et al. Time spent in outdoor activities in relation to myopia prevention and control: a meta-analysis and systematic review. Acta Ophthalmol. 2017; 95: 551-66.

25. Gwiazda J. Treatment options for myopia. Optom Vis Sci. 2009; 86: 624-8.

26. McBrien NA, Stell WK, Carr B. How does atropine exert its anti-myopia effects? Ophthalmic Physiol Opt. 2013; 33: 373-8.

27. Bedrossian RH. The effect of atropine on myopia. Ann Ophthalmol. 1971; 3: 891-7.

28. Chua WH, Balakrishnan V, Chan YH, Tong L, Ling Y, Quah BL, et al. Atropine for the treatment of childhood myopia. Ophthalmology. 2006; 113: 2285-91.

29. Fan DS, Lam DS, Chan CK, Fan AH, Cheung EY, Rao SK. Topical atropine in retarding myopic progression and axial length growth in children with moderate to severe myopia: a pilot study. Jpn J Ophthalmol. 2007; 51: 27-33.

30. Tong L, Huang XL, Koh AL, Zhang X, Tan DT, Chua WH. Atropine for the treatment of childhood myopia: effect on myopia progression after cessation of atropine. Ophthalmology. 2009; 116: 572-9.

31. Fang YT, Chou YJ, Pu C, Lin PJ, Liu TL, Huang N, et al. Prescription of atropine eye drops among children diagnosed with myopia in Taiwan from 2000 to 2007: a nationwide study. Eye (Lond). 2013; 27: 418-24.

32. Saw SM. A synopsis of the prevalence rates and environmental risk factors for myopia. Clin Exp Optom. 2003; 86: 289-94.

33. Shih YF, Chen CH, Chou AC, Ho TC, Lin LL, Hung PT. Effects of different concentrations of atropine on controlling myopia in myopic children. J Ocul Pharmacol Ther. 1999; 15: 85-90.

34. Chia A, Chua WH, Cheung YB, Wong WL, Lingham A, Fong A, et al. Atropine for the treatment of childhood myopia: safety and efficacy of $0.5 \%, 0.1 \%$, and $0.01 \%$ doses (Atropine for the Treatment of Myopia 2). Ophthalmology. 2012; 119: 347-54

35. Polling JR, Kok RG, Tideman JW, Meskat B, Klaver CC. Effectiveness study of atropine for progressive myopia in Europeans. Eye (Lond). 2016; 30: 998-1004.

36. Huang J, Wen D, Wang Q, McAlinden C, Flitcroft I, Chen H, et al. Efficacy Comparison of 16 Interventions for Myopia Control in Children: A Network Meta-analysis. Ophthalmology. 2016; 123: 697-708.

37. Chia A, Chua WH, Wen L, Fong A, Goon YY, Tan D. Atropine for the treatment of childhood myopia: changes after stopping atropine $0.01 \%, 0.1 \%$ and $0.5 \%$. Am J Ophthalmol. 2014; 157(e1): 451-7.

38. Chia A, Lu QS, Tan D. Five-Year Clinical Trial on Atropine for the Treatment of Myopia 2: Myopia Control with Atropine $0.01 \%$ Eyedrops. Ophthalmology. 2016; 123: 391-9. 